\title{
PENERAPAN PERMAINAN TRADISIONAL DALAM UPAYA MENINGKATKAN KEBUGARAN JASMANI PADA MAHASISWA PENJAS ANGKATAN 2019 UNIVERSITAS PGRI ADI BUANA SURABAYA
}

\author{
Gatot Margisal Utomo' ${ }^{1}$,Harwanto² \\ 1 Universitas PGRI Adi Buana Surabaya \\ ${ }^{2}$ Pascasarjana UNIPA Surabaya ${ }^{2}$ \\ E-mail: gatotmargisalutomo@unipasby.ac.id ${ }^{1}$ harwanto@unipasby.ac.id² \\ DOI: https://doi.org/10.36526/kejaora.v6i1.1153
}

\begin{abstract}
ABSTRAK
Tingkat kebugaran mahasiswa perlu mendapat perhatian, mengingat akan padatnya jadwal perkuliahan. Untuk menjaga kebugaran diperlukan alternatif aktifitas fisik, yaitu salah atunya dengan menggunakan permainan tradisional. Tujuan penelitian ini yaitu untuk mengetahui peningkatan kebugaran jasmani dengan menerapkan permainan tradisional pada mahasiswa Penjas Angkatan 2019 Universitas PGRI Adi Buana Surabaya. Adapun jenis dan pendekatan penelitian yang digunakan kali ini yaitu penelitian kuantitatif karena data berupa nominal angka yang didapatkan dari hasil pretest dan posttest, dimana alat ukur yang akan diberikan kepada sampel yaitu dengan memberikan tes TKJI yang terdiri dari tes lari 60 meter, push-up dan sit-up 1 menit, dan lari sejauh 2400 meter. Dari hasil akhir yang didapatkan nilai paired sample test nya sebesar $0.12<0.05$ sehingga ada pengaruh penerapan permainan tradisional dalam upaya meningkatkan kebugaran jasmani pada mahasiswa penjas angkatan 2019 Universitas PGRI Adi Buana Surabaya. Jadi kesimpulan dari hasil penelitian yaitu, permainan tradisional dapat digunakan sebagai salah satu upaya dalam rangka meningkatkan kebugaran jasmani mahasiswa Penjas angkatan 2019 Universitas PGRI Adi Buana Surabaya.
\end{abstract}

Kata Kunci: Permainan Tradisional, Kebugaran Jasmani

\section{PENDAHULUAN}

Dalam menuju zaman yang modern kita jangan sampai meninggalkan warisan atau peninggalan nenek moyang kita, itu dapat dilihat dari bentuk permainan tradisional yang hampir punah dan tidak di ajarkan lagi oleh anak cucu kita pada zaman yang modern ini. Pada zaman dahulu permainan tradisional dibuat sebagai ciri khas kota atau daerah, karena setiap daerah bentuk-bentuk permainan tradisionalnya berbeda, tujuan adanya permainan tradisional yaitu untuk menciptakan rasa kerjasama yang baik, rasa percaya diri yang optimal, dan juga untuk menciptakan tingkat kebugaran jasmani (Kusumawati, 2017).

Dalam model pembelajaran pendidikan jasmani kegiatan yang dilakukan harus bersifar PJOK tematik yang tujuannya agar semua siswa yang melakukan kegiatan tersebut menjadi senang dan gembira, sehingga siswa akan senang melakukan kegiatan olahraga dengan baik (Muhyi, 2008). Biasanya siswa lebih menyukai model pembelajaran jasmani yang berupa permainan, karena bisa dilaksanakan bersama-sama, salah satu bentuk permainan yang bisa dilaksanakan bersama-sama adalah permainan gobak sodor bervariasi. Permainan yang dapat dipraktikkan oleh semua jenis kalangan, baik itu kalangan remaja atau dewasa dan juga dapat di jadikan bahan pembelajaran di tingkat SMP, SMA, bahkan tingkat perguruan tinggi, permainan tradisional ini sampai saat ini berkembang dan sering dilakukan, macam-macam permainan tradisional selain gobak sodor yang masih berkembang sampai saat ini adalah jenis permainan boy-boy an, gebuk bantal, engklek, patil lele, dan lain sebagainya (Kusumawati, 2017). Permainan gobak sodor merupakan permainan yang bertujuan untuk 
Jurnal Kejaora: Jurnal Kesehatan Jasmani dan Olah Raga

ISSN: 2541-5042 (Online)

ISSN: 2503-2976 (Print)

Volume 6 Nomor 1, Edisi April 2021

menciptakan kerja sama antar tim dimana permainan ini dilakukan oleh 2 tim dan masing-masing tim ada 5 pemain, setiap pemain mempunyai peran masing-masing sesuai posisi yang ditempati, permainan ini dilakukan selama kurang lebih 15 menit (Montolalu, 2007).

Gobak sodor permainan tradisional yang terdiri dari 2 grup, yaitu grup jaga dan grup penyerang. Setiap pemain di grup jaga bertugas untuk berjaga dengan cara membuat penjagaan berlapis kebelakang sambil merentangkan tangan agar tidak dapat dilalui oleh lawan. Satu pemain lagi bertugas digaris tengah yang bergerak tegak lurus dari penjagaan lainya (Setiawan \& Triyanto, 2014). Lapangan permainan gobak sodor ini untuk posisi garis jaga biasanya di tandai dengan menggunakan kapur yang bertujuan agar selama permainan berlangsung salah satu kaki tim penjaga posisinya harus tetap di atas garis jaga. Agar kita bisa bermain gobak sodor dengan baik maka kita harus sering melakukan suatu proses latihan. Kerena dengan kita melakukan terus menerus maka peningkatan kita terutama dalam permainan gobak sodor akan lebih meningkat.

Universitas PGRI Adi Buana Surabaya merupakan Universitas yang semua kegiatan belajar mengajarnya dilakukan untuk mengembangkan seluruh aspek positif dalam diri anak didik, berdasarkan hasil observasi yang sudah saya lakukan kurang lebih 3 minggu bahwa kebugaran jasmani mahasiswa Penjas Universitas PGRI Adi Buana Surabaya kurang maksimal, itu dapat dilihat ketika siswa melaksanakan mata kuliah Atletik Lanjut yang dilakukan setiap hari senin dan selasa jam 06.30, hampir setiap 15 menit melakukan aktifitas olahraga yang diberikan oleh dosennya kebugaran siswa menurun itu dapat dilihat banyak mahasiswa angkatan 2019 merasakan lelah dan capek. Penyebab keadaan tersebut dikarenakan oleh beberapa faktor salah satunya pemberian bentuk latihan jasmani yang kurang bervarisasi dan sebagian besar materi yang diberikan tersebut bersifat konvensional (Prastyana \& Putra, 2017). Tanpa memberikan bentuk program latihan, yang dimaksud latihan bersifat konvensional yaitu tanpa memberikan bentuk latihan jadi

setelah melakukan pemanasan (strecing) langsung memulai materi inti (Sukadianto, 2011). Dalam penelitian ini peneliti ingin memberikan bentuk latihan permainan tradisional gobak sodor bervariasi untuk meningkatkan kebugaran jasmani pada mahasiswa Penjas angkatan 2019 kampus semangat pagi Universitas PGRI Adi Buana Surabaya.

Dari latar belakang diatas penulis ingin memberikan bentuk permainan tradisional gobak sodor bervariasi kepada mahasiswa Penjas angkatan 2019 Universitas PGRI Adi Buana Surabaya, sehingga tema dalam penelitian kali ini yaitu: "Penerapan Permainan Tradisional Dalam Upaya Meningkatkan Kebugaran Jasmani Pada Mahasiswa Penjas Angkatan 2019 Universitas PGRI Adi Buana Surabaya".

\section{METODE}

Bentuk kegiatan penelitian dalam penelitian kali ini yaitu kuantitatif karena data pengolahannya berupa nominal angka dan adanya pemberian perlakuan yang akan diberikan pada kelompok. Dalam hal ini yang akan diteliti adalah terkait penerapan permainan tradisional dalam upaya meningkatkan kebugaran jasmani pada mahasiswa Penjas angkatan 2019 Universitas PGRI Adi Buana Surabaya, dengan desain penelitian dengan melakukan tes awal (pretest) dan tes akhir (posstest). Untuk rancangan dalam penelitian ini dapat dilihat dibawah ini:

$$
\begin{array}{lllll}
\mathrm{T}_{1} & \rightarrow & \mathrm{X} & \rightarrow & \mathrm{T}_{2} \\
\mathrm{~T}_{1} & \rightarrow & \sim & \sim & \mathrm{T}_{2} \\
& \text { Gambar 1. Rancangan Penelitian }
\end{array}
$$

Keterangan:

$\mathrm{T}_{1} \quad=$ pretest

$\mathrm{T}_{2} \quad=$ posstest

$\mathrm{X}=$ permainan gobak sodor bervariasi

$\sim \quad=$ kontrol

(Maksum, 2012)

\section{Populasi}

Populasi dapat diartikan sebagai jumlah keseluruhan dari subjek yang akan dijadikan bahan penelitian dalam mengambil data dalam proses penelitian yang akan 
Jurnal Kejaora: Jurnal Kesehatan Jasmani dan Olah Raga

ISSN: 2541-5042 (Online)

ISSN: 2503-2976 (Print)

Volume 6 Nomor 1, Edisi April 2021

dijadikan bahan penelitian dan kemudian untuk dijadikan bahan kesimpulan dalam proses penelitian (Sugiono, 2011). Dalam penelitian ini, populasi sebanyak 37 mahasiswa laki-laki dengan kisaran usia 1920 tahun.

\section{Sampel}

Sampel adalah bagian dari populasi, jadi sampel merupakan suatu perwakilan dari populasi yang berjumlah 37 mahasiswa, tetapi subjek yang akan dijadikan bahan penelitian ini berjumlah 20 mahasiswa, rumus yang dilakukan oleh peneliti dalam menentukan jumlah sampel yaitu dengan menggunakan teknik acak.Proses pengambilan data dalam penelitian ini yaitu dengan memberikan pretest kepada semua sampel, untuk kelompok ekperimen 1 diberikan perlakuan (treatment) permainan tradisional gobak sodor bervariasi, sedangkan untuk kelompok kontrol tidak diberikan perlakuan (treatment). Setelah diberikan treatment selama 2 bulan, maka dilakukan posttest yang tujuannya untuk mengetahui apakah perlakuan yang diberikan selama 2 bulan itu terdapat peningkatan terhadap kelompok eksperimen. Frekuensi latihan 3 kali dalam tiap minggunya. Jumlah tersebut menyesuaikan teori bahwa dalam meningkatkan kebugaran memerlukan waktu latihan 3-5 kali per minggu (Irianto, 2002).

\section{Instrumen Penelitian}

Dalam penelitian ini instrumen yang digunakan yaitu dengan melakukan tes, tujuan diberikan instrumen dalam penelitian ini yaitu untuk mendapatkan data dan untuk mengetahui tingkat kebugaran mahasiswa Penjas angkatan 2019 Universitas PGRI Adi Buana Surabaya setelah diberikan permainan tradisional gobak sodor bervariasi selama 1 bulan. Adapun alat ukur yang digunakan dalam penelitian ini untuk mengetahui tingkat kebugaran jasmani peserta sampel adalah dengan menggunakan tes TKJI dari (Nurhasan, 2013). Melakukan tes TKJI yang meliputi: tes lari 60 meter, sit-up dan push-up selama 1 menit, dan lari 2400 meter.

\section{Teknik Analisis Data}

Untuk hasil penelitian saya ini hasil pengolahan data menggunakan bantuan SPSS (Statistical Program For Social Svience) 21.0.

\section{HASIL DAN PEMBAHASAN}

Untuk mengetahui hasil penelitian dalam penelitian ini analisis yang dipakai dalam penelitian ini sebagai bentuk pengujian hipotesis yaitu dengan menggunakan Paired sampel T test (Uji Beda) (Suharsimi, 2006). Sebelum dilakukan Uji beda Paired sampel T test, dilakukan uji persyaratan data meliputi uji normalitas data, uji homogenitas, dan uji T.

Tabel 1. Descriptive Statistics

\begin{tabular}{llllll}
\hline & N & Min & Max & Mean & Std. Deviation \\
\hline Tes awal & 20 & 2 & 4 & 3.60 & .724 \\
\hline Tes akhir & 20 & 3 & 5 & 4.65 & .649 \\
\hline Tes awal & 20 & 2 & 4 & 3.30 & .652 \\
\hline Test akhir & 20 & 2 & 4 & 2.65 & .674 \\
\hline Valid N (listwise) & 20 & & & & \\
\hline
\end{tabular}

Berdasarkan tabel hasil analisis statistik, diketahui skor rata-rata kelompok eksperimen pada tes awal 3,60, dengan nilai standar deviasi sebesar 0,764 . Sedangkan kelompok kontrol pada tes awal nilai rata-rata yaitu 3,30 , dengan standar deviasi sebesar 0,652 . Sedangkan rata-rata nilai tes akhir pada kelompok eksperimen sebesar 4,65 dan kelompok kontrol 2,65.

Sebelum melakukan uji hipotesis dilakukan uji persyaratan data, yaitu uji normalitas dan homogenitas. 
Jurnal Kejaora: Jurnal Kesehatan Jasmani dan Olah Raga

ISSN: 2541-5042 (Online)

ISSN: 2503-2976 (Print)

Volume 6 Nomor 1, Edisi April 2021

Tabel 2. Test of Homogeneity of Variance

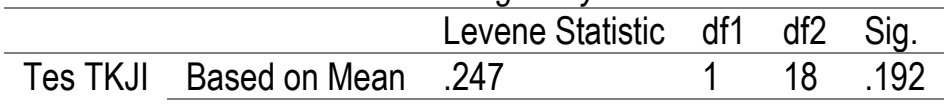

Hasil uji homogenitas diperoleh hasil bahwa nilia Signifikansi sebesar 0,192 lebih besar 0,05. Berdasarkan uji homogenita maka dapat dikatan bahwa data normal dan dapat dilanjutkan ke uji berikutnya.
Setelah dilakuka uji homogenitas, selanjutkanya dilakukan uji normalitas data. Berikut tabel hasil uji normalitas data.

Tabel 3.Tests of Normality

\begin{tabular}{|c|c|c|c|c|c|}
\hline \multirow[t]{2}{*}{ Kelas } & \multicolumn{3}{|c|}{ Kolmogorov-Smirnova } & \multicolumn{2}{|c|}{ Shapiro-Wilk } \\
\hline & Statistic & $d f$ & Sig. & Statistic & $d f$ \\
\hline Pre Test Exsperimen & .423 & 20 & .237 & .824 & 20 \\
\hline Post Tes Exsperimen & .362 & 20 & .183 & .872 & 20 \\
\hline Pre Test Kontrol & .392 & 20 & .107 & .813 & 20 \\
\hline Post Test Kontrol & .347 & 20 & .094 & .826 & 20 \\
\hline
\end{tabular}

Hasil uji normalitas diperoleh hasil

besar dari 0,05. Maka dengan begitu, seluruh bahwa nilia Sig.secaa keseluruhan lebih

data ladalam penelitian ini dikatakan normal.

Tabel 4. Paired Samples Test

\begin{tabular}{|c|c|c|c|c|c|c|c|c|c|}
\hline & & \multicolumn{5}{|c|}{ Paired Differences } & \multirow{3}{*}{\multicolumn{2}{|c|}{$t \quad d f$}} & \multirow{3}{*}{$\begin{array}{l}\text { Sig. } \\
(2- \\
\text { tailed) }\end{array}$} \\
\hline & & \multirow[b]{2}{*}{ Mean } & \multirow[b]{2}{*}{$\begin{array}{c}\text { Std. } \\
\text { Deviation }\end{array}$} & \multirow[b]{2}{*}{$\begin{array}{l}\text { Std. } \\
\text { Error } \\
\text { Mean }\end{array}$} & \multicolumn{2}{|c|}{$\begin{array}{l}95 \% \text { Confidence } \\
\text { Interval of the } \\
\text { Difference }\end{array}$} & & & \\
\hline & & & & & Lower & Upper & & & \\
\hline $\begin{array}{l}\text { Pair } \\
1\end{array}$ & $\begin{array}{l}\text { Pre Test } \\
\text { Eksperimen - } \\
\text { Post Test } \\
\text { Eksperimen }\end{array}$ & -.983 & .724 & .371 & -1.674 & -.638 & 6.217 & 9 & .012 \\
\hline $\begin{array}{l}\text { Pair } \\
2\end{array}$ & $\begin{array}{l}\text { Pre Test } \\
\text { Kontrol - Post } \\
\text { Test Kontrol }\end{array}$ & 352 & 592 & 209 & -.164 & .549 & 2.732 & 9 & .214 \\
\hline
\end{tabular}

Berdasarkan hasil uji paired sampel test menunjukkan nilai siq (2-tailled) $0.12<$ 0.05 untuk kelompok eksperimen. Sedangkan untuk kelompok kontrol siq (2-tailled) $0.214>$ 0.05 .

Berdasarkan hasil pengolahan data yang sudah didapatkan hasil yang meningkat pada pretest dan posttest terhadap pengaruh penerapan permainan tradisional dalam upaya meningkatkan kebugaran jasmani pada mahasiswa penjas angkatan 2019 Universitas PGRI Adi Buana Surabaya. Hasil tersebut ditunjukkan dengan hasil data sebagai berikut: Ditemukan hasil paired sampel test untuk nilai siq (2-tailled) $0.12<$ 0.05 .

Jadi dapat disimpulkan bahwa permainan tradisional gobak bervariasi berpengaruh terhadap peningkatan kebugaran jasmani pada mahasiswa penjas angkatan 2019 Universitas PGRI Adi Buana Surabaya. Sehingga metode permainan tradisional ini bisa dijadikan refrensi atau acuan para guru PJOK atau para Pelatih 
Jurnal Kejaora: Jurnal Kesehatan Jasmani dan Olah Raga

ISSN: 2541-5042 (Online)

ISSN: 2503-2976 (Print)

Volume 6 Nomor 1, Edisi April 2021

untuk dijadikan sebagai program latihan dalam meningkatkan kebugaran jasmani.

Berdasarkan hasil temuan pada penelitian yang telah dilakukan, sejalan dengan hasil penemuan pada penelitian sebelumnya. Penelitian yang sama dalam hal peningkatan kebugaran jasmani dilakukan oleh Mashuri (2018). Berdasarkan temuan tersebut menggambarkan bahwa Setelah mendapatkan perlakuan menngkat sebesar 31,81 atausebesar $35.32 \%$ digambarkan dalam persentase, peningkatan tersebut Dengan demikian dapat disimpulkan bahwa terdapat terdapat peningkatan kebugaran jasmani melalui permainan tradisional gobak sodor siswa kelas V SDN Pulo Lor 4 Jombang, Kec. Jombang. Kab . Jombang. Selanjutnya, penelitian juga sepemahaman dengan hasil penelitian yang dilakukan oleh Permadi (2018). Dalam penelitiannya, terdapat peningkatan kebugaran jasmani melalui permainan tradisional gobak sodor siswa kelas VIII SMP Negeri 2 Sendang Kecamatan Sendang Kabupaten Tulungagung. Berdasarkan hasil penelitian maka, melalui permainan tradisional gobak sodor dapat dijadikan alternatif untuk meningkatkankan kebugaran. Mengingat akan pentingnya kebugaran untuk menunjang aktifitas mahasiswa dalam melaksanakan kegiatan.

Selain bisa menjadikan alternatif pembelajaran penjas permainan tradisionalgobak sodor, juga bisa menjadi motivasi bagi mahasiswa dan di tingkat sekolah. Permainan tradisional gobak sodor juga bisa menjadikan gerak motorik jauh lebih baik dibandingkan sebelumnya. Dimana saat bermain permainan tradisional siswa melakukan gerakan refleks, gerakan terprogram dan banyak gerakan lainnya.

Selanjutnya dalam pembelajaran penjas diera sekarang, harus menerapkan berbagai inovasi untuk lebih menjamin kesesuaian antara kurikulum sebagai dokumen dan proses pembelajaran Pendidikan Jasmani di sekolah,dan permainan tradisional menjadi satu yang cukup baik untuk diterapkan karena merupakan permainan yang kaya akan manfaat, bisa menjadi alternatif pengganti

permainan lain, juga bisa meningatkan motivasi gerak (Widiyatmoko \& Hudah, 2017).

Penting untuk selalu menampilkan jenis-jenis permainan yang memantik semangat atau motivasi mahasiswa atau siswa dalam usaha peningkatan kebugaran. Terbukti bahwa siswa yang aktif ternyata level kebugaran, rasa percara diri dan orientasi hidup lebih baik dibandingkan dengan siswa yang kurang aktif (Purba et al., 2020). Hal itu menunjukkan bahwa, penting bagi kita untuk memberikan alternatif-alternatif lain dalam rangka meningkatkan kebugaran generasi muda sebagai penerus. Mengingat bahwa kebugaran sebagai aspek utama dalam kesehatan dan sebagai kebutuhan dasar manusia.

Sejalan dengan hal itu, Kesehatan sangat penting bagi manusia, karena tanpa kesehatan yang baik, setiap manusia akan sulit dalam melaksanakan aktivitasnya sehari-hari. Salah satu cara agar kesehatan tetap terjaga dengan baik adalah melalui olahraga. Partisipasi masyarakat dalammelakukan kegiatan olahraga semakin meningkat yang ditunjukkan dengan peningkatan partisipasi masyarakat pada indeks pembangunan olahraga (SDI) (Prasetyo, 2013). Peran olahraga dalam mendukung terciptanya sumberdaya manusia yang memiliki kualitas fisik yang baik sudah tidak diragukan lagi. Selain bermanfaat untuk jasmani, olahraga juga berperan dalam pengembangan karakter bangsa.

Selanjutnya, hal-hal yang perlu diperhatikan dalam penggunaan permainan tradisional tentu terdapat beberapa kukurangan yang menjadi catatan peneliti. Mengingat gobak sodor adalah permainan tradisional maka perlu untuk dilakukan modifikasi sehinga mahasiswa tidak bosan dan lebih bervariatif. Selain itu, perlu juga dilakukan modifikasi terhadap peraturan permainan sehingga pemain yang sedang jaga diurutan paling belakang tidak begitu lama menunggu, dan terkesan pasif.

\section{KESIMPULAN}

Berdasarkan hasil analisis statistika pada bab IV yang dianalisis dengan menggunakan bantuan SPSS 21.0 didapatkan hasil paired sampel test utuk nilai 
Jurnal Kejaora: Jurnal Kesehatan Jasmani dan Olah Raga

ISSN: 2541-5042 (Online)

ISSN: 2503-2976 (Print)

Volume 6 Nomor 1, Edisi April 2021

siq (2-tailled) $0.12<0.05$, maka dapat disimpulkan sebagai berikut:

1. Terdapat hasil pengaruh penerapan permainan tradisional dalam upaya meningkatkan kebugaran jasmani pada mahasiswa penjas angkatan 2019 Universitas PGRI Adi Buana Surabaya.

2. Penerapan permainan tradisional memiliki pengaruh yang baik terhadap peningkatan kebugaran jasmani pada mahasiswa penjas.

\section{UCAPAN TERIMA KASIH}

Ucapan terima kasih pada LPPM Universitas PGRI Adi Buana Surabaya yang telah mendukung dalam pelaksanaan penelitian ini, dan tidak lupa untuk semua yang telah terlibat dalam proses penelitian dari awal hingga akhir.

\section{DAFTAR PUSTAKA}

Irianto, D. P. (2002). Dasar Kepelatihan. Yogjakarta: FIK UNY.

Kusumawati, O. (2017). Pengaruh Permainan Tradisional Terhadap Peningkatan Kemampuan Gerak Dasar Siswa Sekolah Dasar Kelas Bawah. 4(2).

Maksum, A. (2012). Metodologi penelitian dalam olahraga. Surabaya: Unesa University Press.

Mashuri, A. (2018). PENGARUH
PERMAINAN GOBAK SODOR
TERHADAPPENINGKATAN
KEBUGARAN JASMANI PADA SISWA
KELAS VSDN PULO LOR 4
JOMBANG(Study
Universitas Mahasiswa
Kediri2018 Putra). Simki-Techsain,
2(4).

Montolalu, B. E. F. (2007). Bermain dan Permainan anak. Universitas Terbuka.

Muhyi, M. (2008). Meningkatkan Kebugaran Jasmani Melalui Permainan dan Olahraga Pencak Sila t. PT Gramedia Widi asaran a Indonesia.

Nurhasan. (2013). Tes dan Pengukuran Pendidikan Olahraga. FPOK UPI.

Permadi, L. S. (2018). PENGARUH PERMAINAN TRADISIONAL GOBAK SODOR TERHADAP TINGKAT KEBUGARAN JASMANI SISWA KELAS VIII SMP NEGERI 2 SENDANG 